\title{
ISOLATION OF BRANCHED CHAIN AMINOACIDS (VALINE, LEUCINE AND ARGININE) USING MAGHEMITE PARTICLES
}

\author{
1,2 Natalia CERNEI, 1,2 Pavel KOPEL, ${ }^{3}$ Pavel HORKY, ${ }^{1,2}$ David HYNEK, 1,2 Ondrej ZITKA, \\ 1,2 Vojtech ADAM \\ ${ }^{1}$ Department of Chemistry and Biochemistry, Faculty of AgriSciences, Mendel University in Brno, \\ Czech Republic, EU, vojtech.adam@mendelu.cz \\ ${ }^{2}$ Central European Institute of Technology, Brno University of Technology, Brno, Czech Republic, EU \\ ${ }^{3}$ Department of Animal Nutrition and Forage Production, Faculty of AgriSciences, Mendel University in Brno, \\ Brno, Czech Republic, EU
}

https://doi.org/10.37904/nanocon.2019.8497

\begin{abstract}
In this paper, we report the optimal conditions for the isolation and preconcentration of branched chain amino acids (BCAAs) - leucine, valine and arginine from different types of matrix, such as tissue, plasma, blood, bacteria or cells. Herein, we focused on the synthesis of paramagnetic particles able to isolate and immobilize amino acids and thus preconcentrate it for subsequent analysis on ion-exchange liquid chromatography with VIS detector. We modified nanomaghemite $\left(\mathrm{\gamma}-\mathrm{Fe}_{2} \mathrm{O}_{3}\right)$ by multi walled carbon nanotubes (MWCNT) and hyaluronic acid as the functional carriers providing excellent affinity properties. Our paramagnetic particles have potential for better isolation of BCAAs mainly from plasma or bacteria and in the future they can also be applied as a platform of delivery system.
\end{abstract}

Keywords: Ion Exchange Chromatography, Maghemite, MWCNT, BCAAs, valine, leucine, arginine

\section{INTRODUCTION}

Branched chain amino acids (BCAAs) play metabolic and physiologic roles in the processes in mammalian bodies, for example protein synthesis [1], signalling pathways [2], and metabolism of glucose, may be used as possible marker of diabetes mellitus type 2. Oxidation of BCAAs may increase fatty acid oxidation and play a role in obesity. BCAAs, play major physiological roles in the brain function and/or in immunity [3]. They are involved, for example in the cardiac hypertrophy in regulation of proteosynthesis [4]. BCAAs are used in many cases as a bioactive part of cationic peptides with antimicrobial activity (mostly leucine-rich, arginine-rich and valine-rich, having high antibacterial activity and perfect hemocompatibility) $[5,6]$. Paramagnetic particles (PMPs) are very important for targeted drug delivery directly to the centre of the disease under different conditions and, thereby, treat it purposely and/or to enhance the interactions between delivery system and the selected target (cancer cells, bacteria's cells etc.) [7]. Maghemite particles for isolation or preconcentration of BCAAs from fluids of the body may be applicable as magnetically-immobilizable recognition elements in biosensors. Nowadays, various methods are developed for branched chain amino acids (BCAAs) such as valine, leucine and arginine determination. Most of them are based on chromatography (GC, LC, UHPLC) [8] with tandem of mass spectrometry (MS) [9], IEC [10] or CE [11]. In our paper, we decided to use ion exchange chromatography with post-column ninhydrin derivatization and VIS detector for valine, leucine and arginine detection [10].

\section{METHODOLOGICAL BASES AND EXPERIMENTAL PART}

\subsection{Chemicals}

Arginine of purity $99 \%$ was obtained from Sigma Aldrich (St. Louis, Missouri, USA). Solution of arginine for preparing of calibration curve was prepared in the dilution buffer $\mathrm{Na}$ : TDG $\left(\mathrm{N}_{3} \mathrm{Na}-0.10 \mathrm{~g}, \mathrm{NaCl}-\right.$ 
$11.5 \mathrm{~g}, \mathrm{C}_{6} \mathrm{H}_{8} \mathrm{O}_{7}-14$ per $1 \mathrm{~L} \mathrm{H}_{2} \mathrm{O}$ ). For experiment were used Citric acid, $\mathrm{NaCl}, \mathrm{N}_{3} \mathrm{Na}, \mathrm{TDG}, \mathrm{HCl} 35 \%$ from Sigma - Aldrich (St. Louis, Missouri USA), Ninhydrin from Sigma - Aldrich (St. Louis, Missouri,USA), Methylcellosolve (Ingos, Prague, Czech Republic), $\mathrm{SnCl}_{2}$ (Ingos, Prague, CzechRepublic).

\subsection{Ionex chromatography}

An AAA 400 (Ingos, Czech Republic) liquid chromatography apparatus was used for determination of amino acids. The system consists of a glassy filling chromatographic column and steel precolumn, two chromatographic pumps for transport of elution buffers and derivatization reagent, cooled carousel for 25 test tubes of 1.5-2.0 mL volume, dosing valve, heat reactor, VIS detector and cooled chamber for derivatization reagent. Chromatographic columns for transfer of elution buffers and derivatization reagent are able to work at flow $0.01-10 \mathrm{~mL} \cdot \mathrm{min}^{-1}$ under a maximum pressure of $40 \mathrm{MPa}$. Volume of injected sample was $100 \mu \mathrm{L}$ with an accuracy of application RSD of about $1 \%$. A two-channel VIS detector with a $5 \mu \mathrm{L}$ flow volume cuvette was operated at wavelengths of 440 and $570 \mathrm{~nm}$.

\subsection{SEM characterization of modified maghemite particles}

Structure and elemental composition of paramagnetic microparticles were characterised by electron microscope. For documentation of the selected nanomaterials a FEG-SEM MIRA XMU (Tescan, a.s., Brno, Czech Republic) was used. This model is equipped with a high brightness Schottky field emitter for low noise imaging at fast scanning rates. The SEM was fitted with Everhart-Thronley type of SE detector, high speed YAG scintillator based BSE detector, panchromatic CL Detector and EDX spectrometer. The MIRA 3 XMU system is based on a large specimen chamber with motorized stage movements $130 \times 130 \mathrm{~mm}$. Samples were coated by $10 \mathrm{~nm}$ of carbon to prevent sample charging. A carbon coater K950X (Quorum Technologies, Grinstead, United Kingdom) was used. For automated acquisition of selected areas a TESCAN proprietary software tool called Image Snapper was used. The Accepted Article software enables automatic acquisition of selected areas with defined resolution. Different conditions were optimized in order to reach either minimum analysis time or maximum detail during overnight automated analysis. An accelerating voltage of $15 \mathrm{kV}$ and beam currents about $1 \mathrm{nA}$ gives satisfactory results regarding maximum throughput.

\subsection{SCEM determination of relative current response of modified maghemite particles PMPS}

Identification of the relative current response before and after BCAA binding was performed using a scanning electrochemical microscope, Model 920D (CH instruments, Austin, TX, USA). Measurements were carried out with $10 \mu \mathrm{L}$ of paramagnetic articles in concentration of $10 \mu \mathrm{g} \cdot \mathrm{mL}^{-1}$ mixed in ACS water. The electrochemical microscope consisted of a $10 \mathrm{~mm}$ platinum disc probe electrode with a potential of $0.2 \mathrm{~V}$. Another platinum disc electrode was used with an O-ring as the conducting substrate with a potential of $0.3 \mathrm{~V}$. During scanning, the particles were attached to the substrate platinum electrode by magnetic force from a neodymium magnet. The liquid used in the analyses consisted of $5 \%$ ferrocene in methanol $(\mathrm{w} / \mathrm{v})$ mixed in ratio $1: 1$ with $0.05 \%$ $\mathrm{KCl}$ in water $(\mathrm{v} / \mathrm{v})$. Measurements were performed in a Teflon cell with volume of $1.5 \mathrm{~mL}$ according to the following parameters: amperometric mode, vertical scan area $40 \mu \mathrm{m} \times 40 \mu \mathrm{m}$, and scan rate of $30 \mu \mathrm{m} \cdot \mathrm{s}^{-1}$.

\subsection{X-ray fluorescence analysis of PMPs}

XRF elemental analysis of PMPs was carried out on Xepos (SPECTRO analytical instruments GmbH, Kleve, Germany) fitted with three detectors: Barkla scatter - aluminium oxide, Barkla scatter - HOPG and Compton/secondary molybdenum respectively. Analyses were conducted in Turbo Quant cuvette method of measuring. Analysis parameters were set to - measurement duration: $300 \mathrm{~s}$, tube voltage from 24.81 to 47.72 $\mathrm{kV}$, tube current from 0.55 to $1.0 \mathrm{~mA}$, with zero peak at $5000 \mathrm{cps}$ and vacuum switched off. 


\subsection{Preparation of microparticles}

\section{MAN 26}

Maghemite particles were prepared by sodium borohydride $\left(\mathrm{NaBH}_{4}\right)$ reduction of iron chloride $\left(\mathrm{FeCl}_{3} \cdot 6 \mathrm{H}_{2} \mathrm{O}\right)$. To $1 \mathrm{~g}$ of $\mathrm{FeCl}_{3} \cdot 6 \mathrm{H}_{2} \mathrm{O}$ dissolved in $100 \mathrm{~mL}$ of water was added with stirring $0.2 \mathrm{~g}$ of NaBH 4 in $10 \mathrm{~mL}$ of $3.5 \%$ $\mathrm{NH}_{3}$. After hydrogen release, the mixture was heated for $2 \mathrm{~h}$ at $100^{\circ} \mathrm{C}$ and left on stirrer overnight. The product was collected by magnet and washed 5 times with water. Product was dispersed in water $(150 \mathrm{~mL}), 100 \mathrm{mg}$ of MWCNT was added and agitated on Biosan OS-10 for $2 \mathrm{~h}$ followed by addition of $1 \mathrm{~mL}$ of hyaluronic acid $(1 \mathrm{~g} \mathrm{HA} / 50 \mathrm{~mL})$, stirred 2 hours and separated with magnet. Finally, product was washed with water and dried at $40{ }^{\circ} \mathrm{C}$. Product weight was $0.3 \mathrm{~g}$.

\section{RESULTS AND DISCUSSION}

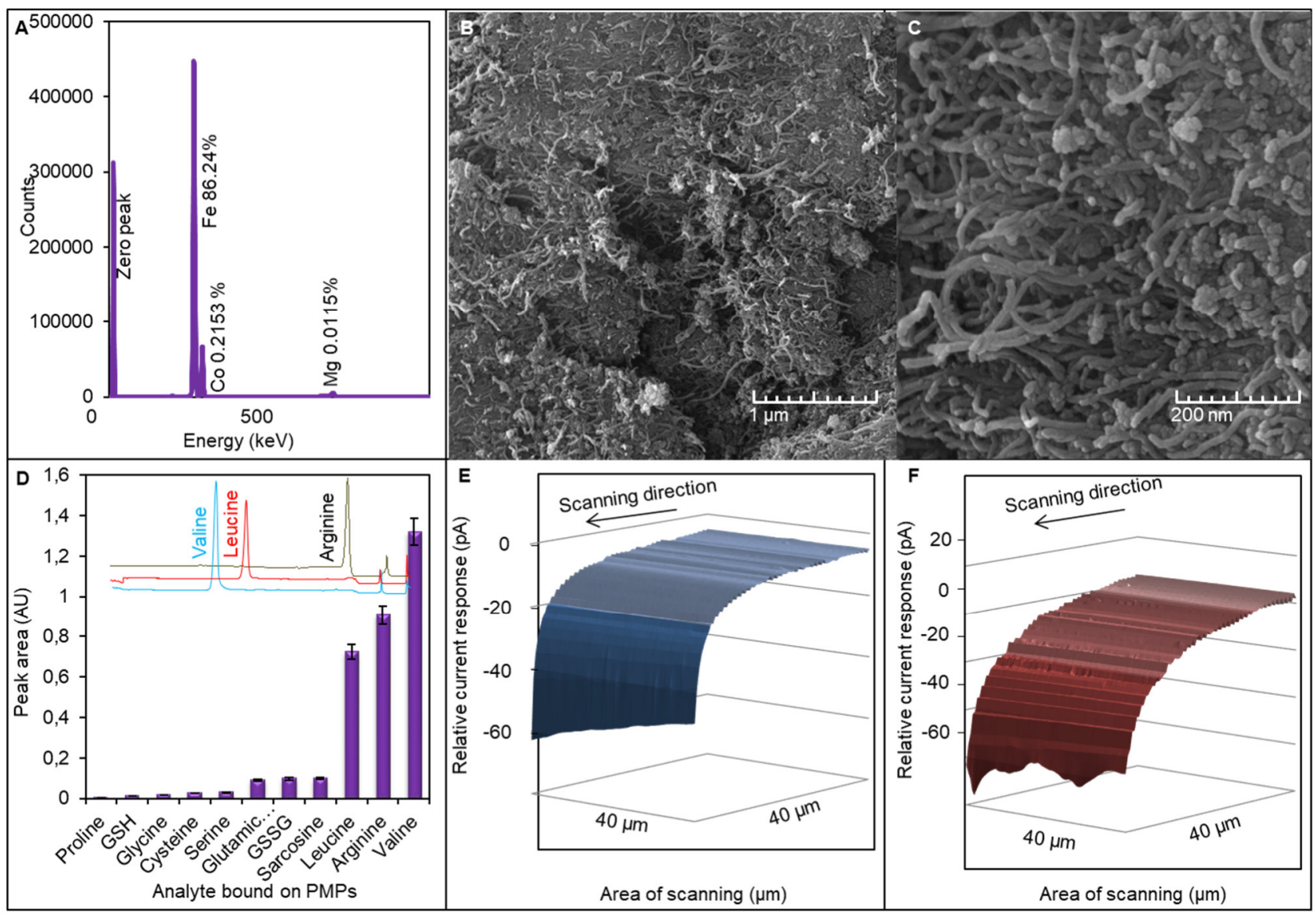

Figure 1 Characterization of paramagnetic particles called MAN 26. (A) X-ray fluorescence elemental analysis, showing elemental composition of paramagnetic microparticles. (B) SEM scan of paramagnetic microparticle in resolution of $1 \mu \mathrm{m}$, showing the particle size. (C) SEM scan of paramagnetic microparticle microparticle surface in resolution of $200 \mathrm{~nm}$. (D) IELC results showing ability of paramagnetic microparticles bound required substances specifically. (E) SECM scan showing relative current response of paramagnetic microparticle without valine bound. (F) SECM scan of paramagnetic microparticle with valine bound showing increased relative current response.

Aim of our study was primarily isolation and 2D separation of the branched chain amino acids (BCAAs), based on the adsorption on the paramagnetic microparticles and subsequent determination using ion-exchange liquid 
chromatography (IEC). We modified maghemite with MWCNT and hyaluronic acid, and these PMPs showed excellent properties for binding of valine (recovery $31.82 \%$ ) (Figure 1D). We used Britton-Robinson buffer with $\mathrm{pH} 2$ which causes (BCAAs) protonation that leads into a positive charging of molecules due to its $\mathrm{pl}=$ 5.97 for valine, $\mathrm{pl}=5.98$ for leucine and $\mathrm{pl}=10.76$ for arginine. Interaction between surface of magnetic microparticles and positively charged molecules provides the binding between them. These interactions depend on isoelectric points of amino acids, which are in this mode behaving as the ion-exchangers. Other amino acids and tripeptides such as GSH and GSSG, showed also relative good recoveries (arginine recovery $15.1 \%$, leucine $22 \%$, sarcosine $0.9 \%$, GSSG $0.5 \%$, GSH $0.45 \%$, serine $0.88 \%$ ).

After confirmation of capability to bind amino acids valine, leucine and arginine, we carried out a different characterization of PMPs. Primarily characterization was XRF analysis providing information about element composition of microparticles. In the Figure 1A can be seen that iron was determined to be the most abundant element (Fe represented $86.24 \%$ ), cobalt (Co represented $0.2153 \%$ ) and magnesium (Mg represented $0.0115 \%$ ). In Figure 1B can be seen a micrograph expressing microparticles surface and morphology in resolution of $1 \mu \mathrm{m}$ for MAN 26 and in Figure 1C is SEM micrograph of PMP surface in resolution of $200 \mathrm{~nm}$. On these micrographs, MWCNTs are well seen together with some smaller particles (in $\mathrm{nm}$ dimensions) of maghemite on their surface, but most of maghemite forms aggregates with MWCNTs on its surface. Although, there are some nanoparticles of maghemite, it is better to speak about microparticles that were formed after drying process and used for experiments. In Figures 1E, F can be seen 3D images, expressing a relative current response of PMP surface without valine and with valine bound.

\section{CONCLUSION}

In our study, we synthesized new paramagnetic microparticles able to bind branched chain amino acids as possible markers of obesity. Leucine and valine are important markers for diagnosis of diabetes mellitus type 2 and arginine is possible marker of metastatic tumor growth. The paramagnetic microparticles (MAN 26) have potential to better isolation from the samples of plasma, cells, bacteria's cells or tissue and in future can serve for application as a platform of delivery system and/or application as a biosensor.

\section{ACKNOWLEDGEMENTS}

\section{The financial support from NAZV QK1720349 is highly acknowledged. QK1720349 "Nanoparticles zinc as an alternative to antibiotics in pigs"}

\section{REFERENCES}

[1] SHE, P.X.; OLSON, K.C.; KADOTA, Y.; INUKAI, A.; SHIMOMURA, Y.; HOPPEL, C.L.; ADAMS, S.H.; KAWAMATA, Y.; MATSUMOTO, H.; SAKAI, R., et al. Leucine and protein metabolism in obese zucker rats. Plos One 2013, 8.

[2] SHE, P.X.; OLSON, K.C.; KADOTA, Y.; INUKAI, A.; SHIMOMURA, Y.; HOPPEL, C.L.; ADAMS, S.H.; KAWAMATA, Y.; MATSUMOTO, H.; SAKAI, R., et al. Leucine and protein metabolism in obese zucker rats. Plos One 2013, 8.

[3] BABCHIA, N.; CALIPEL, A.; MOURIAUX, F.; FAUSSAT, A.M.; MASCARELLI, F. The pi3k/akt and mtor/p70s6k signaling pathways in human uveal melanoma cells: Interaction with b-raf/erk. Invest. Ophthalmol. Vis. Sci. 2010, 51, 421-429.

[4] ZHANG, S.H.; ZENG, X.F.; REN, M.; MAO, X.B.; QIAO, S.Y. Novel metabolic and physiological functions of branched chain amino acids: A review. J. Anim. Sci. Biotechnol. 2017, 8.

[5] LI, M.; VERDIJK, L.B.; SAKAMOTO, K.; ELY, B.; VAN LOON, L.J.C.; MUSI, N. Reduced ampk-acc and mtor signaling in muscle from older men, and effect of resistance exercise. Mech Ageing Dev 2012, 133, 655-664. 
[6] MA, Q.Q.; LV, Y.F.; GU, Y.; DONG, N.; LI, D.S.; SHAN, A.S. Rational design of cationic antimicrobial peptides by the tandem of leucine-rich repeat. Amino Acids 2013, 44, 1215-1224.

[7] DONG, N.; MA, Q.; SHAN, A.; LV, Y.; HU, W.; GU, Y.; LI, Y. Strand length-dependent antimicrobial activity and membrane-active mechanism of arginine - and valine-rich beta-hairpin-like antimicrobial peptides. Antimicrob Agents Chemother 2012, 56, 2994-3003.

[8] CHOMOUCKA, J.; DRBOHLAVOVA, J.; HUSKA, D.; ADAM, V.; KIZEK, R.; HUBALEK, J. Magnetic nanoparticles and targeted drug delivering. Pharmacol Res 2010, 62, 144-149.

[9] AL-TANNAK, N.F. Uhplc-uv method for simultaneous determination of perindopril arginine and indapamide hemihydrate in combined dosage form: A stability-indicating assay method. Sci. Pharm. 2018, 86.

[10] MESONZHNIK, N.V.; POSTNIKOV, P.V.; APPOLONOVA, S.A.; KROTOV, G.I. Characterization and detection of erythropoietin fc fusion proteins using liquid chromatography-mass spectrometry. J. Proteome Res. 2018, 17, 689-697.

[11] DUSKOVA, K.; VESELY, S.; SILVA, J.D.; CERNEI, N.; ZITKA, O.; HEGER, Z.; ADAM, V.; HAVLOVA, K.; BABJUK, M. Differences in urinary amino acid patterns in individuals with different types of urological tumor urinary amino acid patterns as markers of urological tumors. In Vivo 2018, 32, 425-429.

[12] DE CARVALHO, R.C.; MATHIAS, T.R.D.; NETTO, A.D.P.; MARQUES, F.F.D. Direct determination of amino acids in brewery worts produced by different processes by capillary zone electrophoresis. Electrophoresis 2018, $39,1613-1620$. 